\title{
Resistência à Erosão por Cavitação de Aços Inoxidáveis Austeníticos CrMnSiN Depositados por PTA
}

\author{
(Cavitation Erosion Resistance of CrMnSiN Austenitic Stainless Steels Deposited by PTA)
}

\author{
Hélio Ormeu Ribeiro' ${ }^{2}$ Augusto José de Almeida Buschinelli², Jair Carlos Dutra², \\ Ana Sofia Clímaco Monteiro D'Oliveira ${ }^{3}$ \\ ${ }^{1}$ Instituto Federal de Santa Catarina/IFSC, DAMM, Florianópolis,SC, Brasil, hormeu@ifsc.edu.br \\ ${ }^{2}$ Universidade Federal de Santa Catarina/UFSC,EMC,Florianópolis, SC,Brasil, buschi@emc.ufsc.br \\ ${ }^{3}$ Universidade Federal do Paranál DEMC, Curitiba, PR, Brasil, sofmat@ufpr.br
}

\begin{abstract}
Resumo
A erosão por cavitação deteriora componentes em serviço, tais como partes metálicas de bombas de água, válvulas e, em especial, pás de turbinas hidráulicas, sendo nesse último caso responsável por elevados prejuízos ligados tanto aos custos da manutenção direta, como sobretudo às perdas por interrupção na geração de energia elétrica. Dentre os materiais aplicados no reparo por soldagem de danos por cavitação incluem-se aços inoxidáveis tradicionais tipo AISI 308 e 309, aços inoxidáveis ao Co e ligas à base de Co (stellites), caracterizando-se essas últimas pela maior sensibilidade a trincas, dificuldade de esmerilhamento e pelo mais alto custo. Nesse contexto este trabalho buscou formular, depositar e analisar o desempenho de aços inoxidáveis austeníticos CrMnSiN, soldados pelo processo PTA. A resistência à erosão por cavitação foi avaliada segundo a norma ASTM G 32-92. A microestrutura foi caracterizada por microscopia ótica e microscopia eletrônica de varredura e a formação de martensitas 'e , induzida pela cavitação, foi avaliada por difração de raios-X. A integridade da superfície dos depósitos foi controlada por END, além disso a dureza e a facilidade de acabamaneto por esmerilhamento serviram como critérios para avaliar os revestimentos soldados. Verificou-se que os revestimentos aplicados por PTA eram livres de trincas de solidificação, com baixa porosidade, boa molhabilidade e adequado acabamento superficial. A melhor liga inoxidável austenítica elaborada $(0,03 \% \mathrm{C} ; 0,35 \% \mathrm{~N} ; 13,2 \% \mathrm{Cr} ; 11,8 \% \mathrm{Mn} ; 2,8 \% \mathrm{Si} ; \mathrm{bal} \% \mathrm{Fe})$ mostrou uma resistência à erosão por cavitação próxima aquela das principais ligas comerciais.
\end{abstract}

Palavras-chave: Cavitação, processo PTA, soldagem de revestimento, aços inoxidáveis austeníticos.

\begin{abstract}
Cavitation erosion deteriorates components like metallic parts of water pumps, valves and blades of hydraulic turbines, in this last case being responsible for high economical losses, associated to direct maintenance costs, but above all due to the interruption of the electric power generation. Among the materials usually applied in the welding repair of cavitation erosion are included the common stainless steels AISI 308 and 309, special Co-alloyed stainless steels and Co-base alloys (stellites), whereby these have as handicap a higher susceptibility to cracking, the difficult in finishing by grinding and the higher cost. In this context this work had the purpose to design, develop and evaluate CrMnSiN austenitic stainless steels, as deposited by the PTA process. The cavitation erosion resistance was evaluated using the vibratory ultrasonic test according ASTM G32-92. The microstructure was analyzed by means of optical and scanning electronical microscopy and the nature of phases present in the coatings - the cavitation induced formation of martensites 'and - was estimated by $x$-rays diffraction. Besides that the surface quality as examined by NDT, the hardness and the feasibility of finishing by grinding, where all evaluation criteria of the welded deposits. It was verified that the coatings applied by PTA were free from solidification cracks, had low porosity, good wetability and adequate surface finishment. The best austenitic stainless steel developed $(0,03 \% \mathrm{C} ; 0,35 \% \mathrm{~N} ; 13,2 \% \mathrm{Cr} ; 11,8 \% \mathrm{Mn} ; 2,8 \% \mathrm{Si}$; bal \% Fe) showed a cavitation erosion resistance quite near the most resistant commercial alloys.
\end{abstract}

Key-words: Cavitation, PTA process, hardfacing, austenitic stainless steels.

\section{Introdução}

Os danos pela erosão por cavitação são responsáveis por elevados prejuízos associados à manutenção de turbinas

(Recebido em 08/01/2010; Texto final em 18/06/2010). Artigo originalmente publicado no CONSOLDA 2009, Piracicaba, SP, Outubro de 2009. hidráulicas, tanto aqueles oriundos diretamente do reparo por soldagem, como, sobretudo devido à inevitável interrupção na geração de energia elétrica. Justifica-se assim a busca por novos procedimentos e tecnologias de deposição, bem como por materiais de revestimentos que permitam atingir maior tempo de vida útil dos equipamentos sujeitos ao fenômeno, dilatando ao máximo os intervalos entre as paradas periódicas de uma central geradora.

Os processos de soldagem tradicionalmente empregados 
na deposição de revestimentos resistentes à cavitação são o de eletrodos revestidos e o MIG/MAG. Atualmente cogita-se da aplicação do processo PTA - Plasma a Arco Transferido, por características vantajosas como: elevada produtividade, excelente qualidade do depósito, alta estabilidade do plasma bem como maior flexibilidade na formulação de ligas.

No que diz respeito a materiais de adição, até meados da década de 90 as áreas sujeitas à cavitação em turbinas hidráulicas eram recuperadas exclusivamente por soldagem com eletrodos revestidos de aços inoxidáveis austeníticos tradicionais tipos E308 e E309. Entretanto a relativamente baixa resistência desses aços à erosão por cavitação motivou o desenvolvimento de aços inoxidáveis ao Co (ligas Ireca e suas variantes comerciais como Cavitec e Hidroloy) de mais alta resistência, porém de alto custo. Ligas à base de cobalto (Stellites) têm excelente resistência à cavitação, porém além do custo proibitivo apresentam susceptibilidade a trincas, acrescida da dificuldade no acabamento final por esmerilhamento [1-4].

O desenvolvimento dos consumíveis comerciais hoje aplicados norteou-se pela conjunção de fatores esquematicamente mostrados na figura 1. De acordo com essa linha de desenvolvimento [5-10] são os seguintes os requisitos fundamentais de uma microestrutura adequada para resistir à erosão por cavitação:

a) Microestrutura austenítica $\gamma(\mathrm{CFC}) \rightarrow$ para que seja viável a transformação de fase in-situ, ou seja, que energia absorvida durante a cavitação promova a formação de martensita $\alpha^{\prime}$ (ccc) e/ou martensita $\varepsilon$ (hc);

b) Baixa energia de falha de empilhamento (EFE), responsável pelo modo de deslizamento planar, com conseqüente refinamento microestrutural e elevado encruamento (maclas finas) quando submetido à cavitação;

c) Metaestabilidade da fase austenítica $\rightarrow$ do nível das temperaturas Md e Ms dependerá o tempo de incubação para a transformação de fase para um mesmo nível de energia de deformação imposta.

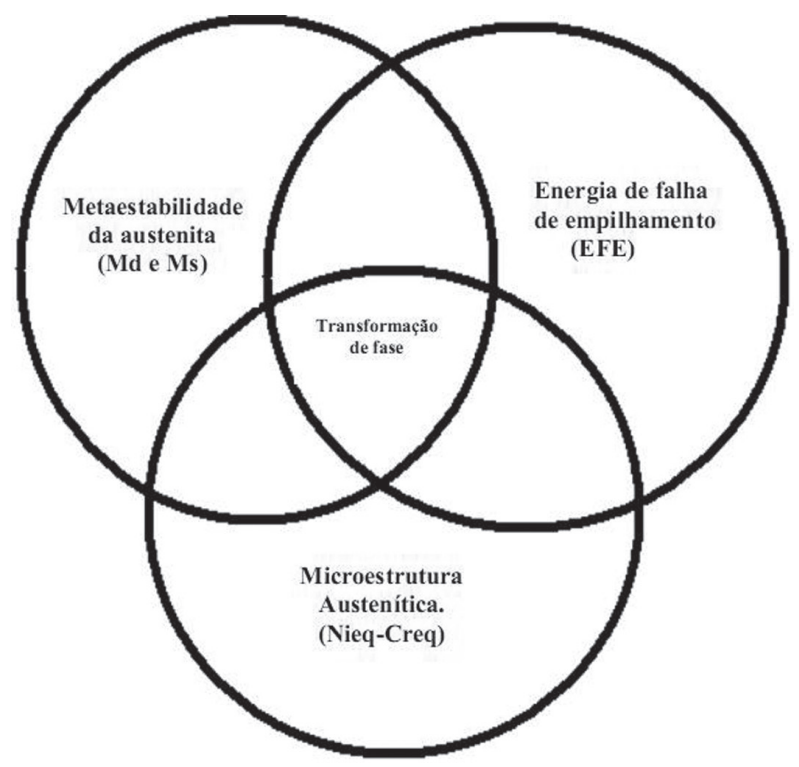

Figura 1 - Conjunção de fatores para obtenção de microestrutura resistente à erosão por cavitação [11].
Apesar do bom desempenho na proteção contra cavitação, comparativamente aos usuais E308 e E309, os consumíveis disponíveis no mercado brasileiro têm custo elevado, seja pelo fato de serem importados como também por manterem em sua composição teor relativamente alto de Co (cerca de $10 \%$ em peso) $[3,4]$. Nesse contexto a pesquisa e desenvolvimento de novos materiais, em particular de aços inoxidáveis de menor custo, isentos de cobalto, para revestir superfícies cavitadas ou sujeitas à cavitação, bem como a busca por uma metodologia de desenvolvimento e deposição de novas ligas, são atividades de relevante interesse especialmente na área hidrelétrica. Neste sentido esse trabalho teve por objetivo formular, depositar e avaliar aços inoxidáveis $\mathrm{CrMnSiN}$, de elevada resistência à erosão por cavitação e baixo custo, que atendessem aos requisitos de boa soldabilidade e funcionabilidade.

Com a proposição de uma liga com alto Mn buscase, em primeiro lugar, em conjunto com o $\mathrm{N}$, outro forte elemento gamagênico, obter uma microestrutura austenítica no revestimento no estado como soldado. É reconhecido que o Mn incrementa a solubilidade do $\mathrm{N}$, aumenta a resistência à trinca de solidificação e contribui para diminuir a energia de falha de empilhamento (EFE) [7].

Substituindo o Ni pelo Mn nos aços austeníticos produz-se um aumento em torno de três vezes, na resistência à cavitação [3]. As ligas propostas possuem elevado conteúdo de Mn uma vez que o mesmo regula a presença das martensitas $\varepsilon$ e $\alpha$ '. Quanto mais elevado o conteúdo de Mn, mais incentivada é a transformação $\gamma \mathrm{P} \varepsilon$.

No caso do Si, Reed (1988) [13] mostra dados de sua forte influência na EFE, chegando a diminui-la em $4,7 \mathrm{~mJ} / \mathrm{m}^{2}$ por cada incremento de $1 \%$ em peso. $\mathrm{O}$ autor analisou ainda a dependência da EFE com a composição química e verificou a influência positiva desse elemento na transformação $\gamma \mathrm{P} \varepsilon$

Menon et al (1996) [2], utilizando depósitos com PTA, verificaram que o Cr é benéfico na diminuição da EFE, porém de modo menos pronunciado. Scharamm e Red em 1975 mediram a EFE para várias ligas de aço inoxidável comercial e verificaram que os elementos $\mathrm{Cr}, \mathrm{Si}, \mathrm{Mn}$ e $\mathrm{N}$ tendem a diminuí-la [6]. Observa-se desse modo que a adição de altos teores de cromo tende a ser benéfica, no entanto, esse elemento é ferritizante e, portanto um teor alto apesar de diminuir a EFE, não contribui na formação da estrutura austenítica.

Schramm e Red em 1975 verificaram que os elementos Ni e C tendem a aumentar EFE [6]. Para Simoneau et al (1987) [6] os intersticiais $\mathrm{C}$ e $\mathrm{N}$ atuam combinados e seu nível deve ser $\mathrm{C}+\mathrm{N}$ » 0,35 , já que para valores superiores a taxa de erosão permanece constante. Nessa combinação, segundo esses autores, o C pode ser substituído pelo $\mathrm{N}$ melhorando a ductilidade e resistência à corrosão. $\mathrm{O} \mathrm{N}$ aumenta levemente a EFE para teores de até $0,20 \%$ e induz uma forte diminuição dessa energia para teores maiores. 
Tabela 1- Faixas de composição química nominal pretendida para as ligas experimentais.

\begin{tabular}{|c|c|}
\hline Elemento químico & Variação (\%) \\
\hline $\mathrm{Mn}$ & 10,0 a 25,0 \\
\hline $\mathrm{Si}$ & 2,5 a 4,0 \\
\hline $\mathrm{Cr}$ & 12,0 a 17,0 \\
\hline $\mathrm{N}+\mathrm{C}$ & $» 0,35$ \\
\hline $\mathrm{Fe}$ & Balanço \\
\hline
\end{tabular}

Tabela 2 - Composição química dos pós-metálicos para a elaboração dos metais de adição.

\begin{tabular}{|l|c|c|c|c|c|c|c|c|c|}
\hline Elemento Químico & $\mathrm{C}(\%)$ & $\mathrm{N}(\%)$ & $\mathrm{Mn}(\%)$ & $\mathrm{Cr}(\%)$ & $\mathrm{Si}(\%)$ & $\mathrm{S}(\%)$ & $\mathrm{Al}(\%)$ & $\mathrm{P}(\%)$ & $\mathrm{Fe}(\%)$ \\
\hline Pó de $\mathrm{Cr}$ & & & & 99,4 & 0,15 & & & & \\
\hline Pó de $\mathrm{FeSi}$ & 0,09 & & 0,10 & & 75,38 & 0,003 & 0,95 & 0,01 & 23,37 \\
\hline Pó de $\mathrm{Mn}$ & 0,15 & & 99,18 & & & & & & 0,15 \\
\hline Pó de $\mathrm{Fe}$ & & & & & & & & & 99,85 \\
\hline Pó de $\mathrm{FeCrN}$ & 0,09 & 6,05 & & 61,8 & 0,65 & & & & 31,41 \\
\hline
\end{tabular}

OBS: Composições químicas informadas pelo fornecedor Var Insumos Ltda/SP

Tabela 3 - Parâmetros de soldagem para depósito das ligas na bancada de trabalho PTA-Inversal 300/IMC.

\begin{tabular}{|l|l|}
\hline Parâmetros & $2,01 / \mathrm{min}$ \\
\hline Vazão do gás de arraste & $2,01 / \mathrm{min}$ \\
\hline Vazão do gás de plasma & $15,01 / \mathrm{min}$ \\
\hline Vazão do gás de proteção & $0,38 \mathrm{~kg} / \mathrm{h}$ \\
\hline Taxa de alimentação & $0,27 \mathrm{~kg} / \mathrm{h}$ \\
\hline Taxa de deposição & $10,0 \mathrm{~mm}$ \\
\hline Distância bico peça & $173 \mathrm{~A}$ \\
\hline Corrente media (Im) & $80 \mathrm{~A}$ \\
\hline Corrente de Base (Ib) & $260 \mathrm{~A}$ \\
\hline Corrente de pico (Ip) & $0,25 \mathrm{~s}$ \\
\hline Tempo de base (Tb) e Tempo de pico (Tp) & $33,0 \mathrm{~V}$ \\
\hline Tensão média & $6,4 \mathrm{~cm} / \mathrm{min}$ \\
\hline Velocidade de soldagem & $53,5 \mathrm{~kJ} / \mathrm{cm}$ \\
\hline Energia média & ABNT $1020(150 \mathrm{X} 100$ x $12,7 \mathrm{~mm})$ \\
\hline Substrato & $\leq 100{ }^{\circ} \mathrm{C}$ \\
\hline Temperatura de interpasse & $90^{\circ}$ \\
\hline Ângulo de ataque & Argônio com $99,99 \%$ de pureza \\
\hline Gás de proteção, arraste e plasma & \\
\hline
\end{tabular}

\section{Materiais e Metodologia}

\subsection{Preparação dos corpos de prova}

Um levantamento detalhado dos fundamentos metalúrgicos de um material metálico resistente à cavitação e uma série de testes preliminares (Ribeiro, H., 2007) nortearam a seleção dos principais elementos de liga $(\mathrm{Mn}, \mathrm{Cr}, \mathrm{Si}, \mathrm{N}$ e C) e suas respectivas faixas de composição, que constam da tabela $1 . \mathrm{Na}$ tabela 2 está a composição química dos vários pós triturados de metais puros, ligas binárias e ternárias, que entraram como matéria prima, mediante mistura e homogeneização adequada, na formulação dos metais de adição inoxidáveis experimentais.

As misturas foram depositadas em três camadas em substrato de aço 1020 (figura 2), através do processo de soldagem PTA - Plasma a Arco Transferido automático empregando-se parâmetros e variáveis de soldagem previamente definidos (tabela 3). O PTA além de ser uma das tecnologias mais avançadas na área de deposição de revestimentos, tem um papel importante no estudo do desenvolvimento de novos metais de adição. 


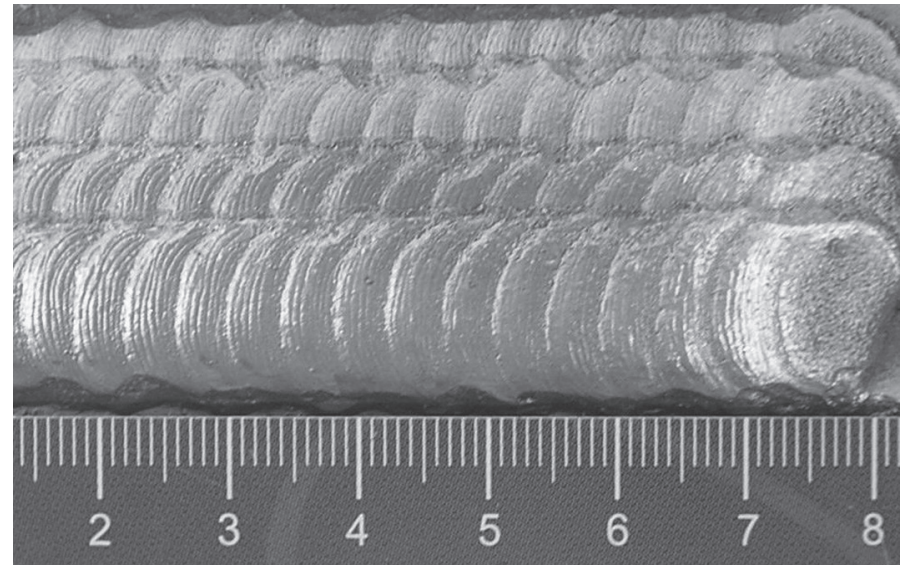

Figura 2 - Aspecto da superfície do corpo de prova com depósito em três camadas (espessura do substrato $=12,7 \mathrm{~mm}$ )

\subsection{Soldabilidade, composição química, diluição, dureza e microestrutura.}

A soldabilidade das ligas experimentais foi avaliada através de exame visual e por líquidos penetrantes da presença de trincas e porosidade nos revestimentos soldados. Por análise visual foram avaliadas a molhabilidade e acabamento superficial. Além disso a microdureza Vickers (HV0.2) serviu como parâmetro indireto da viabilidade de esmerilhamento para acabamento superficial do revestimento.

A composição química dos revestimentos 'como soldados' foi determinada via espectroscopia de absorção atômica (AAS) em laboratório de firma credenciada pelo INMETRO em São Paulo. Na análise microestrutural foram empregadas microscopia ótica e microscopia eletrônica de varredura; na avaliação da transformação martensítica induzida pela cavitação aplicou-se a técnica da difração de raios-X. As amostras metalográficas foram preparadas de acordo com procedimentos usuais de lixamento e polimento mecânicos, sendo exigido para revelação da microestrutura um reagente composto de $5 \mathrm{ml}$ de $\mathrm{HCl}, 1,0 \mathrm{~g}$ de ácido pícrico, 100ml de álcool etílico.

A análise do grau de diluição, como um critério para avaliar a influência do substrato em aço carbono no revestimento, ocorreu via software para análise de imagens macrográficas, obtidas por estereoscópio em corte transversal dos cordões depositados.

\subsection{Ensaios acelerados de cavitação}

Os corpos de prova para o ensaio de cavitação foram retirados por corte mecânico, a superfície a ser exposta a cavitação foi usinada, lixada e posteriormente polida com alumina $1 \mu \mathrm{m}$. Empregou-se o ensaio ultra-sônico vibratório obedecendo à norma ASTM G32-92. Conforme ilustrado na figura 3, escolheuse a variante do método indireto, cuja taxa de erosão é cerca de $40 \%$ a $60 \%$ daquela do método direto $[4,5]$. As vantagens dessa opção residem tanto na maior facilidade de usinagem, como em especial na mais simples montagem/retirada dos corpos de prova para execução dos ensaios, que exigem interrupções sucessivas para pesagem e determinação da taxa de erosão.

\section{Resultados e Discussões}

\subsection{Composição química do metal de adição e dos revestimentos}

Uma séria de ligas foi depositada obedecendo às variações químicas propostas pela tabela 1 e os parâmetros de soldagem definidos na tabela 3. A tabela 4 e 5 apresentam a composição química nominal das ligas de adição e a composição química da superfície dos revestimentos para três depósitos respectivamente.

Tabela 4 - Composição química nominal das ligas de adição.

\begin{tabular}{|c|c|c|c|c|c|}
\hline Liga & $\mathrm{N}(\%)$ & $\mathrm{Cr}(\%)$ & $\mathrm{Mn}(\%)$ & $\mathrm{Si}(\%)$ & $\mathrm{Fe}(\%)$ \\
\hline L01 & 0,4 & 17,0 & 15,0 & 4,0 & Balanço \\
\hline L02 & 0,4 & 17,0 & 25,0 & 4,0 & Balanço \\
\hline L03 & 1,0 & 17,0 & 20,0 & 4,0 & Balanço \\
\hline
\end{tabular}

Tabela 5 - Composição química da superfície dos revestimentos.

\begin{tabular}{|c|c|c|c|c|c|c|}
\hline Liga & $\mathrm{C}(\boldsymbol{\%})$ & $\mathrm{N}(\boldsymbol{\%})$ & $\mathrm{Cr}(\boldsymbol{\%})$ & $\mathrm{Mn}(\boldsymbol{\%})$ & $\mathrm{Si}(\boldsymbol{\%})$ & $\mathrm{Fe}(\boldsymbol{\%})$ \\
\hline L01 & 0,04 & 0,15 & 14,2 & 10,9 & 3,3 & Balanço \\
\hline L02 & 0,04 & 0,20 & 15,4 & 18,2 & 3,1 & Balanço \\
\hline L03 & 0,03 & 0,35 & 13,2 & 11,8 & 2,8 & Balanço \\
\hline
\end{tabular}

Confrontando os resultados dessas duas tabelas observou-se que, houve uma diminuição do percentual dos elementos químicos depositados com exceção do ferro.

No que diz respeito ao Mn, verificou-se uma queda bastante drástica entre o teor nominal da mistura e do revestimento. A possível causa pode ter sido a interação desse elemento com o arco voltaico, pois as partículas de pó de $\mathrm{Mn}$ eram muito pequenas, na media cerca de $25 \mu \mathrm{m}$ : segundo Vergara 2005 [19], quando se trabalha com valores de corrente muito altos, as partículas pequenas são volatilizados no arco plasma e o rendimento de deposição diminui.

A queda do percentual de $\mathrm{Cr}$, explica-se pela presença das partículas não fundidas no revestimento, que fez com que o esse elemento contribuísse com um percentual mais baixo na matriz, bem como pela volatilização no arco voltaico das partículas muito pequenas desse elemento presentes no metal de adição. O decréscimo do Si deu-se em função da formação de uma pequena quantidade de escória vítrea durante a deposição do revestimento.

Admite-se que o carbono no revestimento, mesmo que em baixos teores, possa ser proveniente dos pós que formaram a mistura de adição (tabela 2), bem como devido à diluição desse elemento constituinte do substrato de aço 1020. Entretanto como o hardfacing resultou do depósito de três camadas, apesar da alta energia de soldagem, fica bastante reduzida a contaminação a partir do substrato

Quanto ao $\mathrm{N}$ verifica-se que sua introdução via associação com outros elementos como, por exemplo, através do pó de Fe-Cr-N (tabela 2) foi viável. Observa-se que do percentual de $\mathrm{N}$ do metal de adição, pouco menos de $50 \%$ foram incorporados ao revestimento. Não foram constatadas inclusões de nitretos na microestrutura da liga como soldada, o 

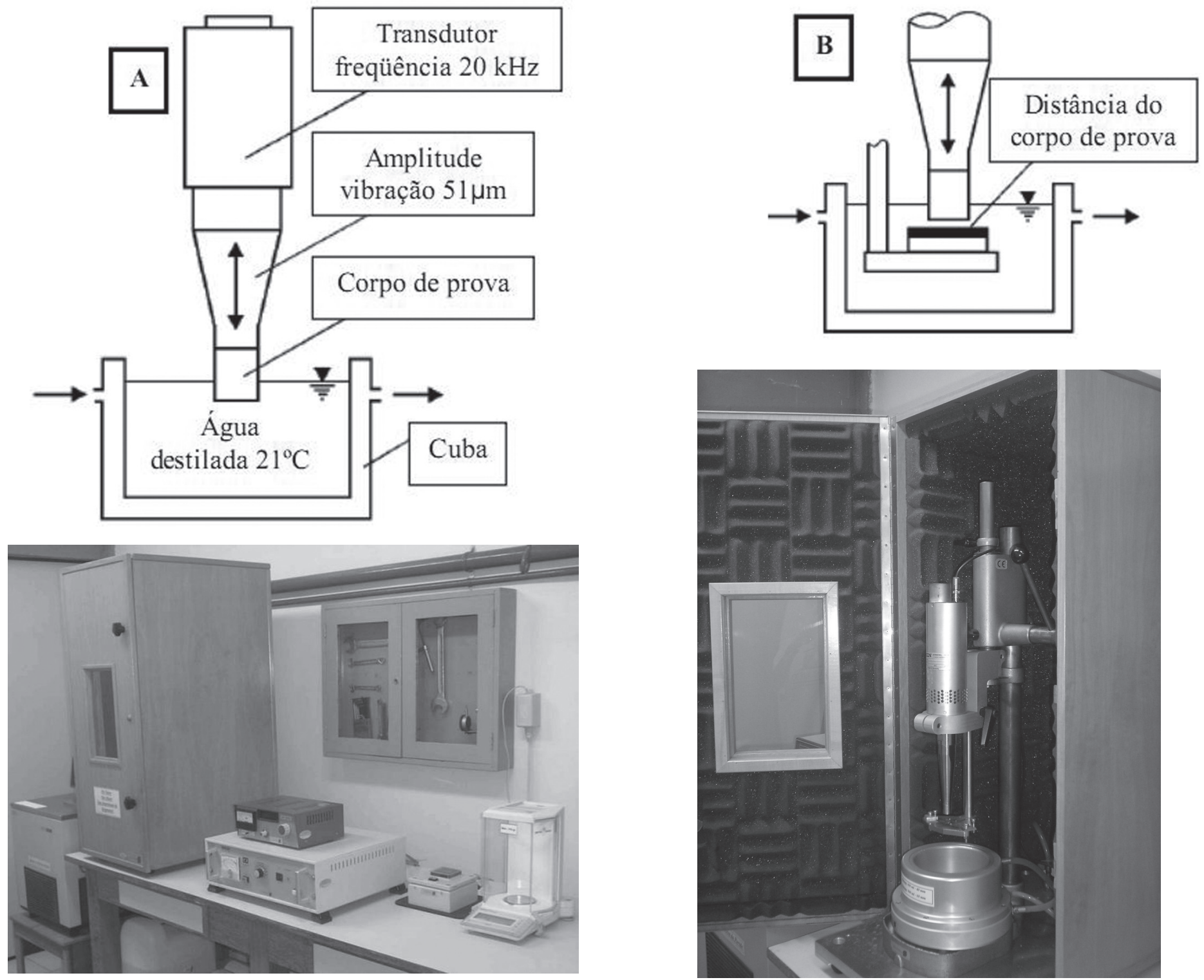

Figura 3 - Teste de cavitação ultra-sônico ASTM G 32. A) método direto e B) método modificado (indireto). C) Equipamento para ensaio de cavitação do Labsolda/EMC/UFSC.

que é uma indicação de que a energia de soldagem foi suficiente para propiciar a fusão da matéria-prima $(\mathrm{FeCrN})$. Em testes preliminares verificou-se a presença de grande quantidade de partículas não-fundidas de $\mathrm{Cr}$ para energia de soldagem inferior a $30 \mathrm{~kJ} / \mathrm{cm}$ (Ribeiro, H.O., 2007).

\subsection{Análise de diluição}

A diluição foi avaliada uma vez que ela tem um importante efeito nos processos onde há fusão do substrato, pois provoca alteração na composição química e conseqüentemente na microestrutura, dependendo do par revestimento-substrato e, portanto pode influenciar de forma significativa na resistência à cavitação dos depósitos [14].

Verificou-se uma forte diluição na primeira camada devido a grande penetração imposta pela alta energia de soldagem utilizada (tabela 6). Essa constatação indicou a necessidade de se produzir revestimentos com mais de duas camadas para que não houvesse interferência de elementos do substrato na avaliação da resistência a erosão por cavitação das ligas experimentais. Pela tabela 6 verifica-se que na terceira camada ocorre uma redução significativa do percentual da diluição resultante $(6,0 \%)$, o que foi julgado suficiente.

Tabela 6 - Diluição dos depósitos das misturas pelo método das áreas.

\begin{tabular}{|c|c|}
\hline Camada & Diluição [\% ${ }^{(*)}$ \\
\hline Primeira & 39,0 \\
\hline Segunda & 15,0 \\
\hline Terceira & 6,0 \\
\hline
\end{tabular}

(*) diluição resultante relativa ao substrato. 


\subsection{Análise da soldabilidade, dureza e microestrutura no estado como soldado.}

Os depósitos apresentaram boa soldabilidade, ou seja, mostraram-se livres de trincas, com baixa porosidade, boa molhabilidade e acabamento superficial adequado.

A viabilidade de esmerilhamento dos revestimentos foi verificada indiretamente através de sua microdureza Vickers (HV 0,2) superficial medida no estado 'como soldado'. Os resultados estão apresentados na tabela 7 .

Apesar da recomendação de empresa do setor de geração hidrelétrica no sentido de que a dureza superficial não seja superior a 27 HRC ou 275 HV [Ribas, F., 1992], o relativamente elevado nível de dureza da liga L03 não representou dificuldade em termos de esmerilhamento e reconstituição do contorno da superfície do hardfacing.

Tabela 7 - Dureza superficial das ligas experimentais.

\begin{tabular}{|c|c|}
\hline Liga & Dureza superficial média (HV 0,2) \\
\hline L01 & 440 \\
\hline L02 & 336 \\
\hline L03 & 325 \\
\hline
\end{tabular}

As análises microestruturais feitas nas ligas L01, L02 e L03, nas regiões a serem cavitadas, estão apresentadas nas figuras 4 a 6 . Na liga L01 (figura 4) a microestrutura era composta de austenita e martensita. $\mathrm{O}$ fato de antes da cavitação a microestrutura já apresentar uma grande quantidade de martensita diminui drasticamente o período de incubação e consequentemente a resistência à erosão por cavitação.
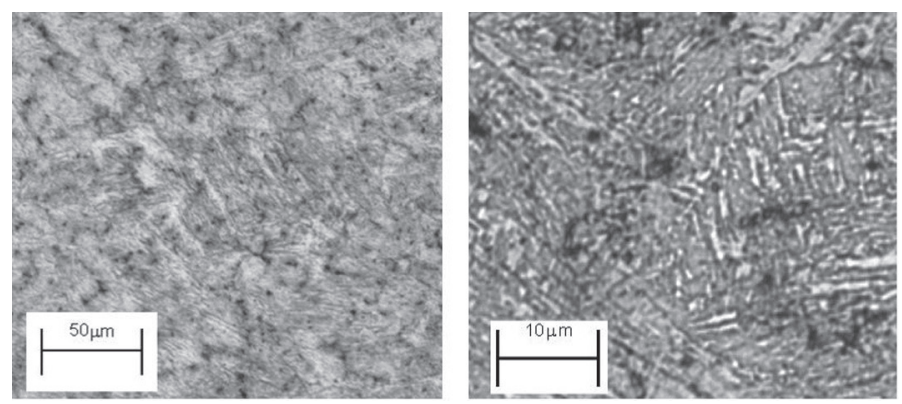

Figura 4 - Liga L01 $(0,04 \% \mathrm{C} ; 0,15 \% \mathrm{~N} ; 14,2 \% \mathrm{Cr} ; 10,9 \% \mathrm{Mn}$; $3,3 \% \mathrm{Si}$; bal Fe). Matriz austenítica martensítica (dureza 440 HV)

A analise microestrutural da liga L02 (figura 5) mostrou uma matriz austenítica com ferrita eutética. Deve-se, no entanto evitar o alto conteúdo de ferrita, uma vez que as estruturas CCC são sensíveis às elevadas taxas de deformação e apresentam elevada EFE, formando estruturas celulares de discordâncias produzidas por deslizamento cruzado que ocorre para deformações muito pequenas. Nesses materiais, as discordâncias vencem facilmente os obstáculos formando-se bandas de deslizamento e grandes zonas plásticas nas pontas das trincas. Eles apresentam também fratura frágil transgranular quando submetidos aos impulsos da cavitação, tornando-os pobre em resistência à erosão por cavitação.
A microestrutura da liga L03 (figura 6) apresentou uma matriz austenítica com a presença de pouca ferrita, portanto uma microestrutura mais adequada para resistir ao fenômeno da cavitação.
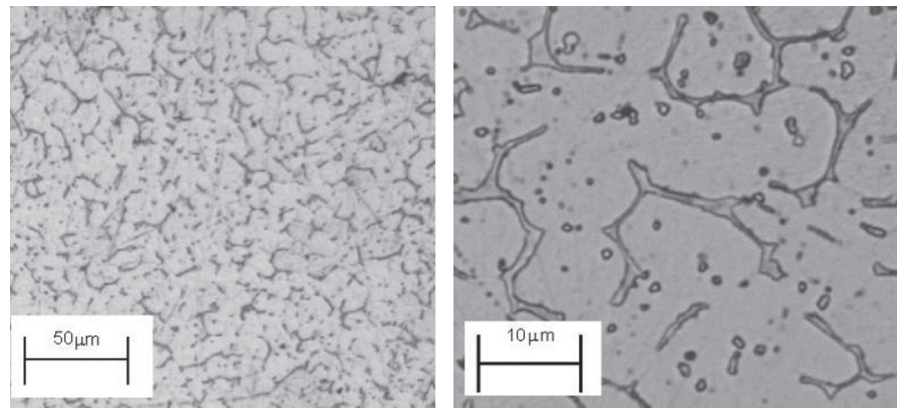

Figura 5 - Liga L02 (0,04\%C; 0,20\%N; 15,4\%Cr; 18,2\%Mn; $3,1 \% \mathrm{Si}$; bal Fe). Matriz austenítica com ferrita eutética (microestrutura AF - dureza $336 \mathrm{HV}$ ).
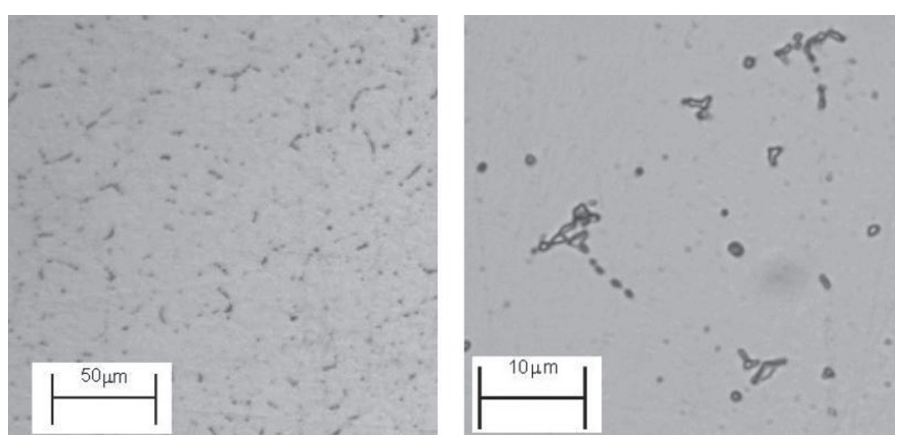

Figura 6 - Liga L03 (0,03\%C; 0,35\%N; 13,2\%Cr; 11,8\%Mn; $2,8 \% \mathrm{Si}$; bal Fe). Matriz austenítica com ferrita eutética (microestrutura AF - dureza 325HV).

\subsection{Avaliação dos revestimentos quanto à erosão por cavitação}

Os resultados de erosão por cavitação são mostrados na figura 7 e tabela 8 juntamente com dados da literatura sobre a resistência de revestimentos dos materiais de referência stellite 6, cavitec e aço inoxidável E 309L. A tabela 8 apresenta os resultados em ordem crescente de resistência à erosão por cavitação, através da avaliação simultânea do período de incubação e a taxa de erosão. Dentre os depósitos efetuados o revestimento que obteve a melhor resposta em termos de erosão por cavitação foi o obtido com a liga L03 $(0,03 \% \mathrm{C} ; 0,35 \% \mathrm{~N}$; $13,2 \% \mathrm{Cr} ; 11,8 \% \mathrm{Mn} ; 2,8 \% \mathrm{Si}$; bal $\mathrm{Fe}$ ) com um período de incubação de 18,6 horas e uma taxa de erosão de $0,40 \mathrm{mg} / \mathrm{h}$.

A figura 8 e a tabela 9 permitem que se compare a resistência à cavitação da liga L03 com materiais comerciais. Pela análise da tabela 9 e figura 8 verifica-se o bom desempenho da liga L03 no revestimento de superfícies submetidas à cavitação, pois sua resposta em termos de resistência a esse fenômeno se aproxima daquele das melhores ligas comerciais destinadas a essa função, tais como as ligas Ireca, Stellite 6 e Cavitec. 
Tabela 8 - Tempo de ensaio, período de incubação e taxa de erosão das ligas experimentais e materiais de referencia.

\begin{tabular}{|c|c|c|c|c|}
\hline $\begin{array}{c}\text { Corpo de } \\
\text { prova }\end{array}$ & $\begin{array}{l}\text { Tempo de } \\
\text { ensaio }(\mathrm{h})\end{array}$ & $\begin{array}{c}\text { Período de } \\
\text { incubação (h) }\end{array}$ & $\begin{array}{l}\text { Taxa de Erosão }(\mathrm{mg} / \mathrm{h}) \\
\text { Método Indireto }\end{array}$ & $\begin{array}{c}\text { Taxa de erosão estimada }(\mathrm{mg} / \mathrm{h}) \\
\text { Método Direto (1) }\end{array}$ \\
\hline E309L & 5,6 & 3,0 & 6,43 & 16,1 \\
\hline L01 & 16,0 & 5,3 & 1,01 & 2,5 \\
\hline L02 & 27,0 & 13,8 & 0,56 & 1,4 \\
\hline L03 & 40,0 & 18,6 & 0,40 & 1,0 \\
\hline Cavitec & 40,0 & 21,4 & 0,33 & 0,8 \\
\hline Stellite 6 & 49,0 & 28,3 & 0,34 & 0,8 \\
\hline
\end{tabular}

(1) método indireto = estipulado 40\% do método direto (Pohl et al 1995, Boccanera, 1999)

Tabela 9 - Taxa de erosão por cavitação da liga experimental L03 e de ligas comerciais.

\begin{tabular}{|l|c|}
\hline Liga & Taxa de Cavitação - Método direto $(\mathrm{mg} / \mathrm{h})$ \\
\hline Aço 1020 & 35,0 \\
\hline Inox 308 & 17,0 \\
\hline CA6NM & 15,0 \\
\hline Inox 301 & 7,7 \\
\hline Conargem E725 & 1,5 \\
\hline Stellite 21 & 1,4 \\
\hline Ireca & 1,0 \\
\hline L03 & 1,0 \\
\hline Stellite 6 & 0,8 \\
\hline Cavitec & 0,8 \\
\hline
\end{tabular}

Referências: $[3,10,15,16,17]$

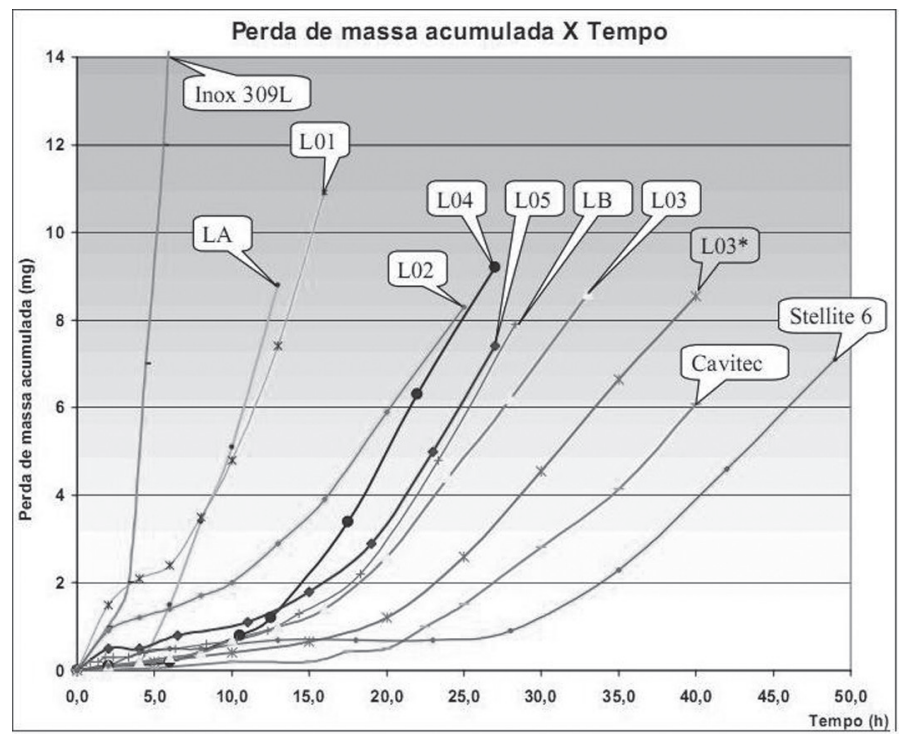

Figura 7 - Resultados do ensaio de cavitação (perda de massa $\mathrm{x}$ tempo) para as ligas experimentais (L01, L02 e L03) e ligas de referencia (E309L, Cavitec, Stellite 6).

\section{5 - Avaliação das fases presentes nos revestimentos antes e após a cavitação}

A figura 9 apresenta um quadro comparativo das fases formadas pelos revestimentos antes e após a cavitação, conforme levantamento efetuado com base em difratogramas de raios-X.

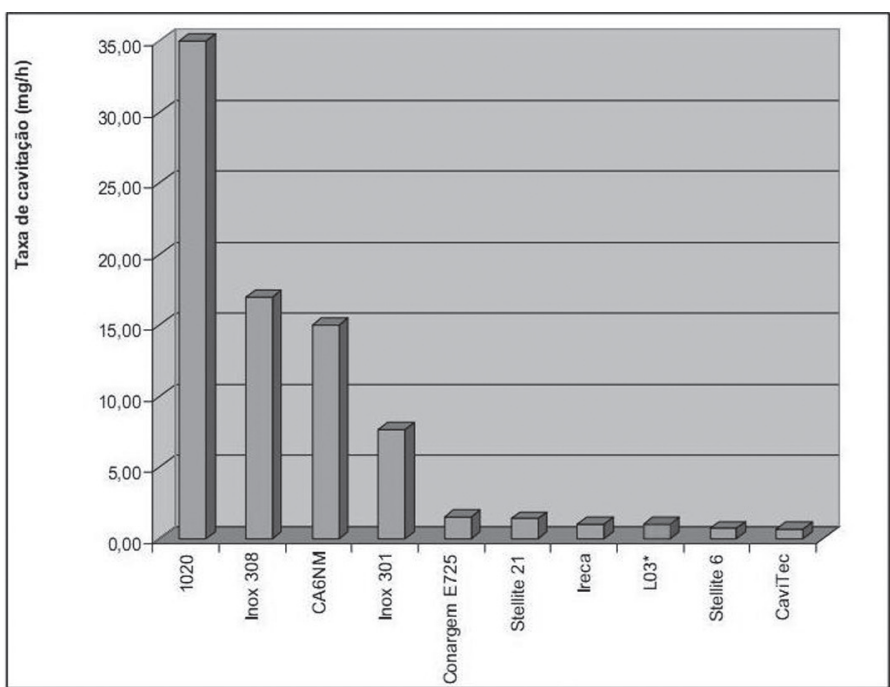

Figura 8 - Comparação da resistência à cavitação da liga L03 e ligas comerciais.

Quanto a liga L01 confirmou-se que a mesma possui uma grande quantidade de martensita formada antes da cavitação, fato já verificado pela análise metalográfica e pelo nível elevado de dureza (figura 4). A presença desse alto teor de martensita antes mesmo de iniciar a cavitação reduziu significativamente o tempo de incubação (tabela 8). Um segundo fato a ressaltar foi a grande quantidade de martensita $\alpha$ ' formada após a cavitação, cerca de $89,1 \%$. Isso se justifica pelo baixo percentual de $\mathrm{Mn}$, 
cerca de 10,9\%, já que esse elemento é forte formador de martensita $\varepsilon$ quando em altos percentuais. A liga apresentou a taxa mais elevada de erosão por cavitação, fato que se deve a presença basicamente da martensita do tipo $\alpha$, que é menos resistente a cavitação do que a martensita $\varepsilon$ uma vez que possui um tamanho de placas maior e é menos tenaz, o que favorece o arrancamento do material e propicia uma erosão mais acentuada.

A liga L02, apresentou um alto percentual de martensita " " formado após a cavitação, o que se deu em função do revestimento apresentar em torno de $18 \% \mathrm{Mn}$. Segundo Röthing et al (1997) [20], ligas com Mn acima de 15\% formam basicamente martensita $\varepsilon$ quando da transformação de fase. Tal transformação de austenita em martensita $\varepsilon$ admite-se seja fator determinante para a liga apresentar um bom desempenho no ensaio de cavitação.

A pequena quantidade de martensita $\varepsilon$ e $\alpha^{\prime}$ presente nas ligas L02 e L03 antes da cavitação pode ter sido gerada pela deformação da austenita durante a preparação da superfície para cavitação, que foi inicialmente usinada, posteriormente lixada e polida mecanicamente.

Após a cavitação observou-se na liga L03 uma microestrutura mista de $\gamma, \varepsilon$ e $\alpha^{\prime}$. O menor percentual de Mn fez com que a quantidade de martensita " $\varepsilon$ " formada durante a cavitação fosse menor. No entanto a resposta melhor a resistência a cavitação estaria provavelmente na menor EFE, em função da presença de um maior quantidade de átomos intersticiais na liga, cerca de $0,38 \% \mathrm{C}+\mathrm{N}$. Como o $\mathrm{N}$ diminui a EFE, sua presença dificulta a possibilidade de deslizamento cruzado, a transformação de fase, prolongando o tempo de incubação e diminuindo a taxa de erosão por cavitação da liga.

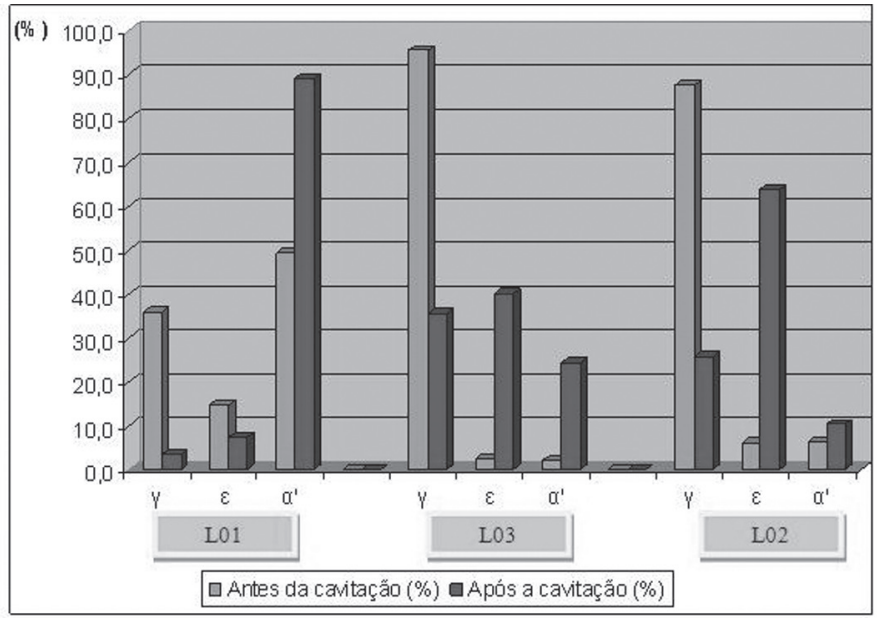

Figura 9 - Comparativo das fases formadas pelos revestimentos L01, L02 e L03.

\section{Conclusões}

* Resistência à cavitação da melhor liga experimental desenvolvida, aço inoxidável austenítico L03 (0,03\%C; $0,35 \% \mathrm{~N} ; 13,2 \% \mathrm{Cr} ; 11,8 \% \mathrm{Mn} ; 2,8 \% \mathrm{Si}$; bal $\% \mathrm{Fe}$ ), é próxima aquela de aços inox ao Co comerciais. A adição dos elementos gamagênicos (Mn e N) permitiu obter uma austenita metaestável, com baixa EFE, transformável em martensita (
- '), que conduziu a um elevado período de incubação e baixa taxa de erosão no regime permanente.

* A soldabilidade operacional da liga desenvolvida mostrou-se satisfatória, devido à boa molhabilidade durante a operação, a baixa porosidade e ausência de trincas no revestimento final.

* A liga L03 apresentou adequada funcionabilidade, permitindo o esmerilhamento sem dificuldade mesmo para uma dureza superficial de $325 \mathrm{HV}$ no estado 'como soldado'.

\section{Agradecimentos}

Ao Instituto Federal de Educação Tecnológica de Santa Catarina (IF-SC), Labsolda da Universidade Federal de Santa Catarina (UFSC) e Laboratório de Engenharia de Superfície da Universidade Federal do Paraná (UFPR).

\section{Referências Bibliográficas}

[1] HART, D.; WHALE, D.; A review of cavitation-erosion reistante weld surfacing alloys for hydroturbines. www.eutetic. castolin.com, acessado em julho de 2005.

[2] MENON, R.; MOSIER,W.C. Stainless steel with improved weldability and cavitation resistence. Brazilian Welding Congress, 1996.

[3] SIMONEAU, R. A new class of hight strain-hardening austenitic steels to fight cavitation erosion. IAHR Symposium, Canada, Sept 1986.

[4] BOCCANERA, L. F. Resistência A Erosão por Cavitação de Revestimentos Depositados por Soldagem e Aspersão Térmica. Tese de Doutorado, UFSC, Florianópolis, 1999.

[5] POHL, M, Cavitation erosion, Practical Metallographic 1996. 33.00.: pgs 168-187

[6]SIMONEAU, R.; LAMBERT,P; SIMONEAU M.; DICKSON J. I. and L'ESPERANCE G. L. 1987: Cavitation erosion and deformation mechanisms of $\mathrm{Ni}$ and $\mathrm{Co}$ austenitic stainless steels. IREQ .

[7]McCAUL, Colin. An advanced cavitation resistant austenitic stainless steel for pumps, Corrosion 96, Paper 415. Nace International Annual Conference and Exposition 1996.

[8] RICHMAN, R. H., McNAUGHTON,P.: Correlation of cavitation erosion behavior with mechanical proprieties of metals wear, p63-83, 1990.

[9] KARIMI, A. Cavitation erosion of austenitic stainless steel and effect of boro and nitrogen ion implantation. Acta metal, vol 37 1989, p 1079-1088

[10] HART, D.; WHALE, D.; A review of cavitation-erosion reistante weld surfacing alloys for hydroturbines. www.eutetic. castolin.com, acessado em julho de 2005.

[11] RIBEIRO, H. O, Desenvolvimento de ligas para revestimentos por pta resistentes à cavitação, Tese de Doutorado do Centro Tecnológico da UFSC, Florianópolis, 2007.

[12] FOLKHARD, E.: Welding Metallurgy of stainless steels, New York, 1984

[13] REED, R. Austenitic stainless steels with on strength at low temperatures. Fracture e Deformation Division . National Bureau of Standarts, 1988. 
[14] D'OLIVEIRA,A.S.C.M.; SLUD, R.; VILAR, R. Soldagem de superfícies por laser a importância do substrato. Congresso da ABS, Curitiba, set 2000.

[15] BOY, J.H.; KUMAR, A.;MARCH, P.;WILLIS, P.;HERMAN, H. Cavitation and erosion resis thermal spray coating, Usacerl, Technical Report 97/118, USA, 1997, p 144

[16] PROCOPIAK, L. A J. Resistência à Cavitação de Três Revestimentos Soldados, Dissertação de Mestrado. UFSC, 1997. [17] RIBAS, F. Relatório de Manutenção no. 037092, 1992, ELETROSUL Centrais Elétricas S.A.

[18] RAO, A. S; KUNG, D. Metallic overlay materials for the optimum cavitation performace of hydraulic turbines, Canadian Eletrical Association, Montreal, Quebec. 1987.

[19] VERGARA, V.M.D. Estudo e desenvolvimento do processo de soldagem plasma de arco transferido alimentado com pó (PTAP) e concepção do equipamento. Tese de Doutorado do Centro Tecnológico da UFSC, Florianópolis, 2005.

[20] RÖTHING, J.; KECKE, H.J.; GARZ, I.; BOSE, E. Metastable austenitic Mn-steels with good tribological and corrosive proprieties - an alternative to $\mathrm{CrNi}$ - steels. Euromat, 1997. 